\title{
Adaptation of Enterprises to Continuous Socio- Economic Changes in a Region
}

\author{
Valentina Smachylo ${ }^{1}$, Veronika Khalina ${ }^{1}$, Olena Kolmakova $^{1 *}$, and Anastasiya Ustilovska $^{1}$ \\ ${ }^{1}$ National University of Civil Engineering and Architecture, Department of Economics, 61001 \\ Kharkiv Sumskaya street 40, Ukraine
}

\begin{abstract}
The article proposes a mathematical model for assessing development of regional resources. The general model includes components which take into account the onset of crises. This model is the basis of the mechanism for assessing socio-economic asymmetry in development of regions.
\end{abstract}

Asymmetry in socio-economic development of regions is inherent to any country of the world. It leads to social tension and political destabilization in regions with low socio-economic development, causing an outflow of capital and population from depressed regions to prosperous ones or even other countries. Accordingly, territories which have advantages are increasing their potential, while the development of lagging ones is becoming more and more problematic. The main objectives of the national regional policy of Ukraine include welfare of its citizens, social justice, integrity and sustainable development of the country. The implementation of these goals largely depends on the overcoming of the existing asymmetry in socio-economic development of regions of Ukraine, formation and development of its modern regional structure, and, consequently, preservation of the national unity. It is asymmetry that intensifies resource flows and influences their redistribution among the regions. The issue of reducing the asymmetry in the development of Ukraine's regions is becoming relevant, and this can be done only through inflow of resources to depressed regions. But here, too, certain contradictions arise: with the advent of new "players", enterprises working in the region are threatened; new "players" have certain difficulties when entering a new market; at the country level, an inflow to one region causes an outflow from another.

Therefore, there is an urgent need to overcome the asymmetry not only in the regional development, but also in the socio-economic system for redistributing resources among the regions. Harmonious development of a region directly depends on success in the development of its enterprises. If we take, e.g., labour resources of the region, the majority of its population (about $44 \%$ of the total population and $90 \%$ of the economically active population) are employed in the regional enterprises. This means that the qualitative and quantitative characteristics of labour resources of the region are shaped by stimulating and motivation mechanisms of its enterprises. It should be noted that the formation of labour resources in a region depends on the policy of forming labour potential of enterprises in the region. Positive trends in development of the economy, increase in the number of enterprises and expansion of the existing ones create additional jobs, and, accordingly, contribute to an inflow of labour resources into the region (Fig. 1).

\footnotetext{
* Corresponding author: elenkolmakova78@gmail.com
} 
Whatever the resources of the region are, their formation is directly affected by enterprises working in it. To connect two socio-economic systems, the authors propose to build a model to forecast and assess development of resources of an individual region.

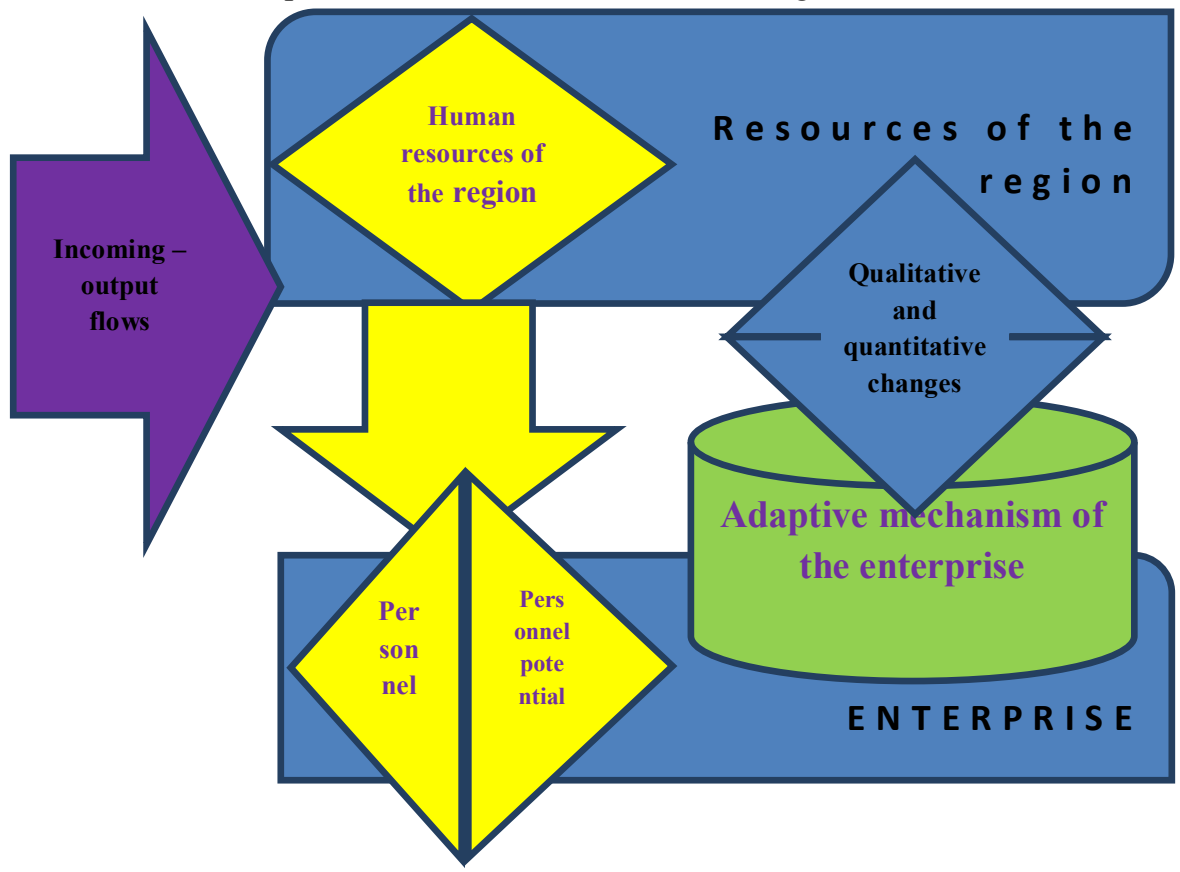

Fig. 1. Impact of enterprise development on the development of regional resources

Before building the forecast and assessment model, it is necessary to investigate factors affecting formation of enterprise environment. The analysis of researches in this area [1-8] has made it possible to summarize and determine the prerequisites for emergence of asymmetry, which can be broken down as follows (Fig. 2):

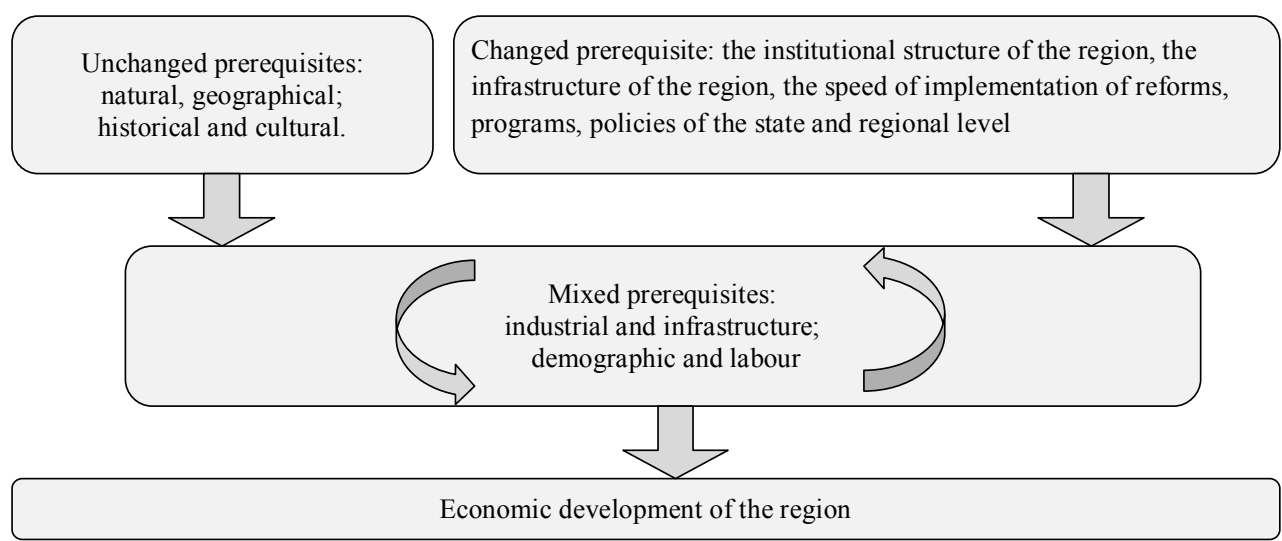

Fig. 2. Prerequisites for the emergence of regional asymmetry

- prerequisites which are almost constant (basic, objective) - those that are formed under the influence of time and are characterized by natural conditions, mentality of the population living in the region, etc. Among these prerequisites scientists single out the 
following: natural and geographical conditions; historical and cultural factors, in this case natural and geographical prerequisites being the basic ones.

- variable prerequisites (secondary, subjective) - those that arose under the influence of reforms, programs, policies at the country and regional level, as well as under the influence of business entities. Among these prerequisites scientists single out the following ones: institutional structure of a region, infrastructure of a region, speed of implementation of reforms, programs, policies at the country and regional levels.

- mixed prerequisites (indirect ones) - those that are formed under the influence of the previous two groups. Researchers recommend including in this group of prerequisites production and infrastructure, demographic and labour ones, which are interconnected. Previously, the location of a production complex depended on the availability of production resources in the region. Overcoming asymmetry in development of regions and optimizing redistribution of regional resources is within the competence of authorities, but it directly depends on enterprises working in the regions. This means that actions of authorities without coordination with the commercial sector will not have a great effect either at the regional or at the country level. That is why the authors propose a model to forecast and assess development of a region. Evaluation of the future state of resources of a region should be the basis for two mechanisms (Fig. 3): 1) a mechanism for managing resources of a region; 2) a mechanism for adapting enterprise to changes in the surrounding socioeconomic environment.

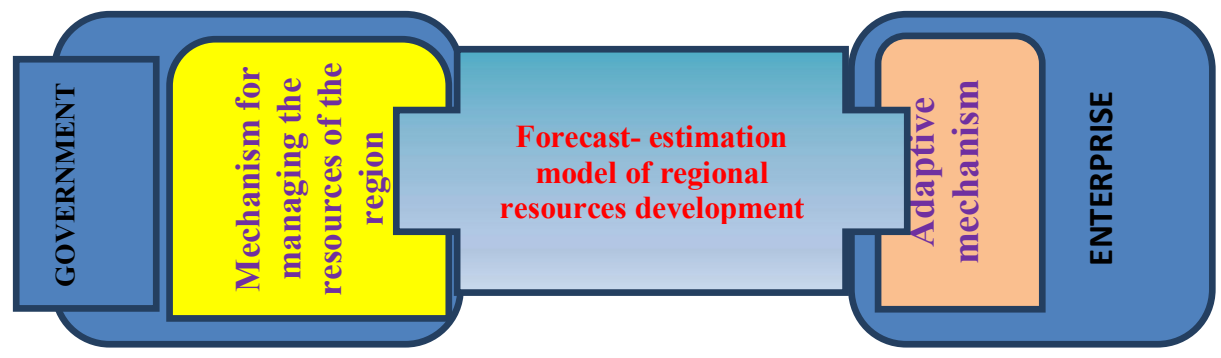

Fig. 3. Coordination of actions of the power of the region and enterprises of the region to overcome the asymmetry of the region

It should be noted that these mechanisms complement each other and the proposed model can become their common component. To obtain an objective assessment of regional asymmetry, a comprehensive approach is needed. It requires consideration of all prerequisites defined in Fig. 1, among which the authors single out a number of characteristics of the level of regional development (and, accordingly, asymmetry): ecological and territorial characteristics - features of the natural landscape, availability of natural resources, environmental conditions, etc. (ET); economic ones - economic development of the region, its production structure, level of income of its enterprises and citizens, profitability of business, increase in GNP, etc. (E); political - political stability, state of the legislative and executive systems, level of the judicial system, institutional structure of a region, infrastructure of a region, speed of implementation of reforms, programs, policies at the country and regional level, existence of corruption in a region, ease of doing business, etc. (P); socio-demographic - social security of citizens, their standard of living, population growth including natural and migratory increase (SD), others - level of innovation in the region, technological development (others).

The authors conducted a study of the available methodologies for assessing the level of development of a region using various characteristics [1-8]. For the research, the methodologies which are used in international practice and have confirmed their feasibility were selected. 
As a result of the research, the author broke down the existing methods and methodologies into 5 groups, based on the criterion of comprehensiveness. Groups were formed depending on the number of characteristics used to assess the state of the region and its development.

Table. 1. Calculation of indicators characterizing asymmetry [9]

\begin{tabular}{|c|c|c|c|c|c|c|c|c|}
\hline \multirow[t]{2}{*}{$\begin{array}{l}\text { Asymmetry } \\
\text { indicators }\end{array}$} & \multirow[t]{2}{*}{$\begin{array}{l}\text { Formulas of calculation and } \\
\text { normative values }\end{array}$} & \multirow[t]{2}{*}{ Components } & \multicolumn{2}{|c|}{$\begin{array}{l}\text { Number of } \\
\text { employees }\end{array}$} & \multicolumn{2}{|c|}{$\begin{array}{l}\text { Volume of } \\
\text { sold products }\end{array}$} & \multicolumn{2}{|c|}{$\begin{array}{l}\text { Number of } \\
\text { enterprises in } \\
\text { the region }\end{array}$} \\
\hline & & & 2016 & 2018 & 2016 & 2017 & 2016 & 2017 \\
\hline $\begin{array}{l}\text { Atkinson } \\
\text { index }\end{array}$ & $\mathrm{A}=1-\frac{\sqrt[n]{\mathrm{x}_{1} \ldots \mathrm{x}_{\mathrm{n}}}}{\overline{\mathrm{x}}}$ & \multirow{5}{*}{ 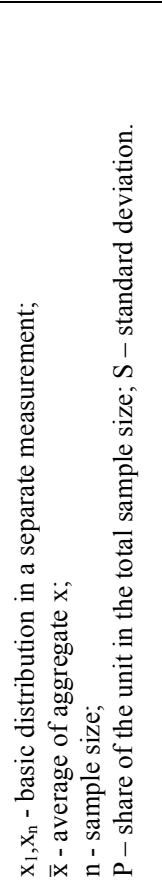 } & 0,09 & 0,08 & 0,50 & 0,18 & 0,28 & 0,16 \\
\hline $\begin{array}{l}\text { Gini } \\
\text { coefficient }\end{array}$ & $\begin{array}{c}\mathrm{G}=1+\frac{1}{\mathrm{n}}-\frac{2}{\mathrm{n}^{2} \overline{\mathrm{x}}}\left(\mathrm{x}_{1}+2 \mathrm{x}_{2}+\right. \\
\left.3 \mathrm{x}_{3}+\cdots+\mathrm{nx}_{\mathrm{n}}\right) \\
\text { A value from } 0 \text { to } 1 \text {. A zero } \\
\text { value characterizes absolute } \\
\text { equality, and } 1 \text { is a complete } \\
\text { inequality. } \\
\end{array}$ & & 0,24 & 0,056 & 0,20 & 0,13 & 0,44 & 0,07 \\
\hline Theil index & $\begin{array}{l}\quad \mathrm{T}_{1}=\frac{1}{\mathrm{n}} \sum_{\mathrm{i}=\mathrm{n}}^{\mathrm{n}}\left(\frac{\mathrm{x}_{\mathrm{i}}}{\overline{\mathrm{x}}} \times \ln \frac{\mathrm{x}_{\mathrm{i}}}{\overline{\mathrm{x}}}\right) \\
\text { Full symmetry }- \text { Teil's index is } \\
\text { equal to } 0 \text {. }\end{array}$ & & 0,10 & 0,09 & 0,85 & 0,21 & 0,4 & 0,18 \\
\hline $\begin{array}{l}\text { Gerfindal } \\
\text { coefficient }\end{array}$ & $\begin{array}{l}\qquad \mathrm{H}=\mathrm{P}_{1}^{2}+\mathrm{P}_{2}^{2}+\cdots+\mathrm{P}_{\mathrm{n}}^{2} \\
\text { The closer to } 10,000 \text { the greater } \\
\text { the asymmetry, the smaller the } \\
\text { coefficient, the less the } \\
\text { asymmetry }\end{array}$ & & 491 & 501,1 & 1893 & 617,5 & 407 & 585,4 \\
\hline $\begin{array}{l}\text { Kurtosis } \\
\text { formula }\end{array}$ & $\begin{array}{l}\text { Es } \\
=\frac{n(n+1) \sum_{i=1}^{n}\left(x_{i}-\bar{x}\right)^{4}}{(n-1)(n-2)(n-3) S^{4}} \\
-\frac{3(n-1)}{(n-2)(n-3)} \\
\text { Less than } 2-\text { insignificant level } \\
\text { of asymmetry, 2-3 - moderate } \\
\text { level of asymmetry, more than } \\
3 \text { high level of asymmetry }\end{array}$ & & 0,85 & 4.93 & 20 & 6.65 & 16 & 4.02 \\
\hline \multicolumn{2}{|c|}{ Level of asymmetry } & & \multicolumn{2}{|c|}{ Low High } & \multicolumn{2}{|c|}{$\begin{array}{l}\text { High } \\
\text { Moderate }\end{array}$} & \multicolumn{2}{|c|}{$\begin{array}{l}\text { Moderate } \\
\text { High }\end{array}$} \\
\hline \multicolumn{3}{|c|}{ Integral coefficient } & 0,90 & 0.98 & 3218 & 19.60 & $\$ 20,91$ & 4.87 \\
\hline \multicolumn{3}{|c|}{ Level of asymmetry } & Low & & High & & \\
\hline
\end{tabular}

Group 1. Narrow assessment of regional asymmetry, including the calculation of: Living Planet Index (ET), Environmental Performance Index (ET), Environmental Vulnerability Index for the Black Sea and Azov regions (ET), Quality of Life Index (SD), Index of Knowledge Societies (SD). Group 2. Assessment of asymmetry using two characteristics, including the calculation of: Index of Sustainable Economic Welfare (SD, E), Human Development Index (E, P), Environmental Sustainability Index (ET, P). Group 3. Assessment of asymmetry with the help of three characteristics, including the calculation of Indicators of Development (Economic, Social \& Environmental) (ET, E, DM). Group 4. Assessment of asymmetry using four characteristics, including the calculation of: Index of Economic Freedom (P, E, SD, others), Competitiveness Index (P, E, SD, others). Group 5. Comprehensive assessment of asymmetry, including the calculation of Indicators of 
Sustainable Development of the UN Commission on Sustainable Development (ET, P, E, DM, others).

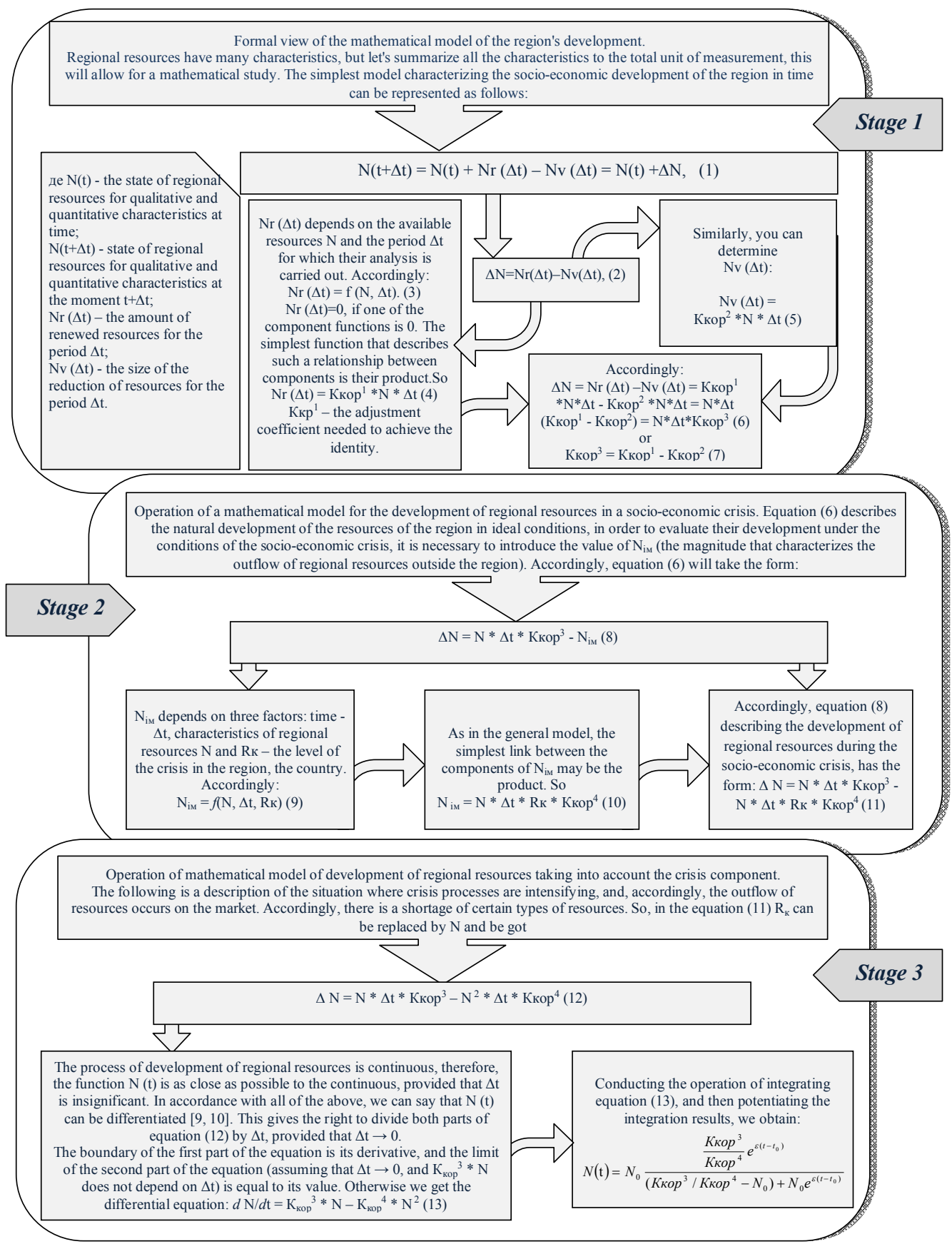

Fig. 4. Stages of development of the forecast-estimation model of regional resources development

Whatever happens in a region, it either affects a person's life, or is the result of their activities. Group 3 and Group 4 contain methodologies which are intended for comprehensive 
assessment of the level of regional development but do not take into account some characteristics. Calculation of Indicators of Sustainable Development proposed by the UN Commission on Sustainable Development is currently the only generally known official methodology for assessing the level of development of a region. In Ukraine, this methodology was adapted and implemented to evaluate regional asymmetry [9]. However, this methodology allows assessing the level of development of a region but does not allow identifying the factors which have conditioned it, only stating the facts.

To eliminate these contradictions, the authors propose a simple but reliable mathematical model for assessing socio-economic development of a region over time, which will allow to evaluate and then model (mitigate, reduce the gap between regions) asymmetry in regional development of a country. The stages of the formation of the mathematical model are presented in Fig. 4.

The developed mathematical model allows predicting the value of $\mathrm{N}(\mathrm{t})$ at any time moment. The authors have determined and summarized the prerequisites for emergence of regional asymmetry, for which a statistical study was conducted. The statistical analysis and grouping of the regions allowed to reveal the asymmetry in their socio-economic development, which was also confirmed by the calculation of other indicators characterizing asymmetry. A grouping of methodologies for comprehensive assessment of regional asymmetry was carried out, which made it possible to propose a model for assessing socio-economic development of a region over time, its formal description being presented. For a detailed development of the model, it is necessary to determine the qualitative and quantitative characteristics of regional resources, develop a mechanism for evaluating these characteristics and constructing a system of integral indicators which will allow to represent the value of $\mathrm{N}(\mathrm{t})$. It would be advisable to develop a document flow, report forms, software to speed up the processing of information and implementation of forecasts.

\section{References}

1. A. Yu. Fedorov Asymmetry of development of regions of the Russian Federation and tools for its smoothing. Questions of modern science and practice. 2, 4 (2006)

2. B. Lavrovsky Measurement of regional asymmetry on the example of Russia. Voprosy ekonomiki. 3 (1999)

3. V. G. Ignatov Asymmetry of the socio-economic development of the regions of the Russian Federation and the main directions of its weakening. TERRA ECONOMICUS. 7, 2 (2009)

4. O. Yu. Krasilnikov Regional asymmetry of structural changes in the economy // Society and the economy, 2 (2001)

5. N. G. Duplenko, L.V. Puryzhova Asymmetry of the potential of socio-economic development of municipalities of the region on the example of the Kaliningrad region. Young Scientist. 19.1 (2014)

6. N. V. Bozhidarnik, V.I. Chuzhikov European model of the identity of regional asymmetries (social aspect). Ukraine: aspects of practice. 6 (2005)

7. Zhovtyak G.A. Estimation of Spatial Asymmetry of Placing Productive Forces in the Economy of the Region. Effective Economics. 9 (2015)

8. I. M. Vakhovich, O.E. Tabalova Regional asymmetry of sustainable development of Ukraine: diagnostics and alignment mechanisms (2012)

9. The State Statistics Service of Ukraine

10. A. D. Pilko, Models of Assessment and Analysis of Asymmetry of Regional Development. Development Economics. 2, 86 (2018) 